\title{
European Journal of Innovation Management
}

Managing the balance of perspectives in the early phase of NPD: A case study from the automotive industry

Kamilla Kohn

\section{Article information:}

To cite this document:

Kamilla Kohn, (2006),"Managing the balance of perspectives in the early phase of NPD", European Journal of Innovation Management, Vol. 9 Iss 1 pp. 44 - 60

Permanent link to this document:

http://dx.doi.org/10.1108/14601060610640014

Downloaded on: 17 August 2015, At: 04:54 (PT)

References: this document contains references to 65 other documents.

To copy this document: permissions@emeraldinsight.com

The fulltext of this document has been downloaded 1084 times since 2006*

\section{CHALMERS}

\section{LIBRARY}

Access to this document was granted through an Emerald subscription provided by emerald-srm:115318 []

\section{For Authors}

If you would like to write for this, or any other Emerald publication, then please use our Emerald for Authors service information about how to choose which publication to write for and submission guidelines are available for all. Please visit www. emeraldinsight.com/ authors for more information.

\section{About Emerald www.emeraldinsight.com}

Emerald is a global publisher linking research and practice to the benefit of society. The company manages a portfolio of more than 290 journals and over 2,350 books and book series volumes, as well as providing an extensive range of online products and additional customer resources and services.

Emerald is both COUNTER 4 and TRANSFER compliant. The organization is a partner of the Committee on Publication Ethics (COPE) and also works with Portico and the LOCKSS initiative for digital archive preservation.

*Related content and download information correct at time of download. 


\section{EJIM \\ 9,1}

\section{4}

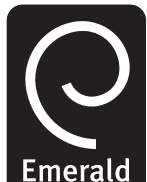

European Journal of Innovation Management

Vol. 9 No. 1,2006

pp. $44-60$

(c) Emerald Group Publishing Limited 1460-1060

DOI 10.1108/14601060610640014

\section{Managing the balance of perspectives in the early phase of NPD}

\author{
A case study from the automotive industry \\ Kamilla Kohn \\ Fenix Research Program, Chalmers University of Technology, Gothenburg, \\ Sweden
}

\begin{abstract}
Purpose - In new product development (NPD), the early phase is considered to be one of the greatest opportunities for improving the overall process, where intensive collaboration between marketing and $R \& D$ is essential. Nevertheless, previous studies indicate the difficulties of creating a thorough concept during the early phase. This paper aims to contribute to understanding why concept creation is difficult during the early phase of NPD.

Design/methodology/approach - This case study involves a single company, and is based on a combination of participant observations and interviews. The participant observations are based on an ethnographic method and the interviews on a hermeneutic approach.

Findings - The findings suggest that the difficulties in creating a strong concept during the early phase are related to the negative conflicts arising between marketing and R\&D. The underlying cause of such conflicts can further be related to the strong interdependencies existing between the functions. Achieving a better understanding of the interdependencies and the different functional views may reduce the negative conflicts which otherwise tend to become barriers to the far-reaching integration needed to develop a thorough concept.
\end{abstract}

Research limitations/implications - As this study is based on a single case, further research is needed in this field in other industries.

Practical implications - Cooperation between functions, as advised in the literature, is not enough and needs to be expanded to cover perspective making and perspective taking in order to move away from the many non-productive conflicts arising during the early phase as well as create thorough concepts.

Originality/value - This paper bridges different bodies of theories related to concept creation and identifies a gap in the existing theories concerning NPD and the early phase.

Keywords Product development, New products, Research and development, Marketing

Paper type Case study

\section{Introduction}

New product development (NPD) in mature industries exposed to fierce competition, e.g. the automotive industry (Breitsprecher et al., 2004; Branstad et al., 1999), is constantly faced with the challenges of developing unique products over shorter periods of time and at lower costs. This has placed great emphasis on the NPD process. Today, one perceived problem in NPD, for both theory and practice, is the numerous late changes when developing a product, causing both time delays and substantial increases in cost. In the literature, arguments have been put forward for more attention being paid to the early phase, where the collaborative input across functions is argued to be critical to success (Griffin and Hauser, 1996; Brown and Eisenhardt, 1995), 
suggesting that having a thorough concept early on may reduce late changes to a product and thus lower the cost, both in terms of time and money (Thomke and Fujimoto, 2000; Wheelwright and Clark, 1992; West, 2000; Clark et al., 1987). The advantage of having a clear concept prior to development is that such a concept brings understanding of what to prioritize during the subsequent development phase and has shown itself in studies to be important to the overall success of NPD (Khurana and Rosenthal, 1997, 1998; Kim and Wilemon, 2002a). The early phase is, therefore, considered to be one of the greatest opportunities for improving the overall NPD process (Thomke and Fujimoto, 2000; Kim and Wilemon, 2002a; Koen et al., 2001). Nevertheless, the creation of a thorough concept is argued to be difficult, and something many companies fail to do (Khurana and Rosenthal, 1997, 1998; Verganti, 1999). However, the literature is vague regarding why it is difficult to create a thorough concept during the early phase.

On the basis of a case study of a European car manufacturer (ECM) in the premium segment, it is argued here that the difficulties of creating a strong concept and product definition during the early phase of NPD are related to the negative conflicts arising between marketing and R\&D. The underlying cause of such conflicts can further be seen to be related to the strong interdependence existing between the functions. Achieving a better understanding of the interdependencies and the different functional views may reduce the negative conflicts which otherwise tend to become barriers to the far-reaching integration needed to develop a thorough concept. These findings contribute to a theory of why concept creation is difficult to achieve during the early phase of NPD as well as to our understanding of how to create far-reaching integration based on collaboration and interaction between marketing and R\&D.

The paper is structured as follows. Firstly, there is an examination of the literature regarding interdependencies, conflicts, and integration in NPD, related to the early phase of NPD. Secondly, there are some notes on the choice of methodology and data collection, followed by a discussion on the case study of ECM, with the perceived problems and opportunities being discussed. Finally, some implications and conclusions are discussed.

\section{Bridging marketing and R\&D}

Based on the definition of NPD as the transformation of a market opportunity into a product as a result of the integrative coupling of market assumptions with technological possibilities (Song and Parry, 1997a, b; Krishnan and Ulrich, 2001; Griffin and Hauser, 1992, 1996), NPD becomes a complex and multifunctional process whereby the dependencies demand collaborative input across the functions. Dependencies further imply conflicts which may be either productive or non-productive as regards work. Conflicts can further be said to express crucial dependencies. The more complex the degree of work - the more complex will be the interdependencies between the functional departments during the different NPD phases. The general perspectives of NPD are often stated to be R\&D, marketing, and manufacturing. Earlier studies indicate, however, that the interdependencies between perspectives and functions vary throughout the development process (Griffin and Hauser, 1996; Song et al., 1998). With regard to the early phase, the strongest interdependencies are identified as being between R\&D and marketing when defining the concept and product definition. The notion of concept development during the early phase of NPD is based on the notion of

\section{Managing the balance of perspectives}


EJIM

9,1

having a phase where a thorough concept is developed via close collaboration between marketing and R\&D, through exploring ideas and knowledge and where different solutions are considered and explored, ending up in a concept and broad product definition (Moenaert et al., 1995; Murphy and Kumar, 1997). Thus, creating a thorough concept and broad product definition wherein prioritized product properties are defined is argued to require the highest level of integration between marketing and R\&D (Gomes et al., 2003; Griffin and Hauser, 1996).

The vision of the product created during the concept phase needs to be a clear representation of what the product should be; as "the light at the end of the tunnel that serves as a focal point for the day-to-day work" during the subsequent development phase when a large number of people are involved and need to have the same vision (Kahn, 1996). Thus, creating the concept requires the mechanisms of proactive thinking, systematic learning, and the integration of various perspectives in order to produce new knowledge concerning what is unknown (Leonard and Straus, 1997; Verganti, 1999). During the subsequent development phase, there is not much time for experimentation and exploration on the concept in the wider perspective across disciplines and functions the early phase enables (Bowen et al., 1994; Kim and Wilemon, 2002a). A well-defined concept during the early phase contributes to a clear picture of what product to develop, while facilitating prioritizations later on during the development process (Khurana and Rosenthal, 1998), and is thus considered to be one of the greatest opportunities for improving the overall NPD process (Kim and Wilemon, 2002a; Koen et al., 2001). The extent to which the concept holds during the development phase of a project can be seen as a comprehensive real-time test of the ability of the organization to handle the early phase. While there is a broad understanding in the literature of the need for a thorough concept early on during NPD, it has also been shown to be difficult (Montoya-Weiss and O'Driscoll, 2000) and the point at which most companies fail (Khurana and Rosenthal, 1997, 1998; Verganti, 1999).

\section{Dealing with conflicts}

Interdependence and differentiation have been identified as a cause of inter-group conflict between marketing and R\&D in NPD (Brett and Rognes, 1986; Ruekert and Walker, 1987), as well as the fact that conflict between R\&D and marketing may be the most damaging and difficult form of conflict to resolve (Crawford, 1977). Leaving negative conflicts unsolved until subsequent phases of development can be very costly since the cost increases in step with how late the changes of concept occur. Of even greater importance is the fact that while these conflicts remain unsolved, there will be no strong common representation of the concept as there is a tendency for divergent ideas regarding what the concept really is. This can be devastating for the entire development project (Crawford, 1977; Griffin, 1997; Hayes et al., 1988).

Walton and Dutton (1969) have studied interdepartmental conflicts in organizations and note that conflicts often develop out of mutual task dependence where there are task-related asymmetries, conflicting performance criteria, dependence on common resources, communication obstacles, and ambiguity of goals. The underlying causes of these differences are argued to be specialization and differentiation in a functional organization, which are an organizational result of handling increased complexity and environmental uncertainty in the different disciplines (Lawrence and Lorsch, 1967). As organizations grow, the specialisation of work increases and, over time, the 
different disciplines will grow apart, each expert in his/her own area but less aware of the others' contributions and ways of working (Griffin and Hauser, 1996). The differences between marketing and R\&D that cause conflicts are often claimed to be based on different values, educational backgrounds, and ways of working (Shaw et al., 2003). This view has been challenged, being argued to be more of a perceptual barrier of stereotypes than one based on actual differences, and thus argued to be reduced by mechanisms enhancing understanding and trust (Gupta et al., 1986b; Griffin and Hauser, 1996). Even though the different functions come under the umbrella of the same corporate goals, the lens through which these goals are interpreted may be different for marketing and R\&D and may thus lead to different functional goals (Souder, 1977). Consequently, understanding one another's goals, trade-offs, and priorities is important when establishing the common goals for the conceptual phase. Further increasing awareness of the interdependencies when creating a product concept between the different functions may lead to less negative conflicts (Ruekert and Walker, 1987).

Though conflicts may be damaging, studies shows that it is fruitful to have a certain degree of conflict between different perspectives in order to develop common knowledge further (Bourgeois, 1980; Galbraith, 1982). Different perspectives bring in different views, and conflicts emerge. Results from studies indicate that conflicts between marketing and R\&D during NPD projects are the rule rather than the exception (Moenaert and Souder, 1990). It has further been shown that where there is full harmony between the different perspectives, when developing a complex product, this is claimed to be either a lack of perspective integration or a strong imbalance of power between the inter-depending functions, possibly further leading to a non-competitive product being developed (Souder, 1988) or just more of the same rather than something new.

While the literature argues for the importance of having a thorough concept developed across functions during the pre-phase of NPD and having results indicating that such a concept is difficult to accomplish, less detailed accounts have been reported regarding the implications of conflicts and how to solve these conflicts in a productive way between the inter-depending functions during the early phase of NPD. The underlying causes of many of these conflicts during the early phase are argued in this paper to be related to a lack of acknowledging and focusing on the strong interdependence between marketing and $\mathrm{R} \& \mathrm{D}$, a relationship also to be found in general NPD studies (Griffin and Hauser, 1996; Gupta et al., 1986a; Kahn, 1996).

\section{Integration as interaction and collaboration}

Acknowledging strong functional interdependencies during the early phase of NPD between marketing and R\&D supports the expressed necessity of strong functional integration and intensive collaboration during this phase. Findings from studies show that successful project performance is achieved when cooperation between marketing and R\&D is on a high level during the early stage of NPD (Gomes et al., 2003; Olson et al., 2001; Rein, 2004; Souder et al., 1998). Furthermore, the lack of such integration is claimed to be the leading contributor to the failure of many new products (Griffin and Hauser, 1996). Even Lawrence and Lorsch (1967) were generally identifying the need for increased integration between functions for successful innovation and product development, based on the then increased need for specialization and differentiation.

\section{Managing the balance of perspectives}


EJIM

9,1

They further identified several differences in the orientations of R\&D and marketing which make integration difficult. This is further supported, in relation to conflicts, by others who argue that more intensive collaboration is needed to overcome the negative attitudes and behaviors resulting from differentiation and specialization in order to support the resolution of conflicts (Gupta et al., 1986b; Griffin and Hauser, 1996; Hauptman and Hirji, 1999; Ruekert and Walker, 1987).

Rather than generally prescribing increased interdepartmental integration, Kahn (1996) discusses the different forms of interdepartmental integration, making a clear distinction between interaction and collaboration. This distinction is important as the choice of when to use which form is related to the organizational context and culture in order to better manage interdepartmental integration. Interaction is described as communication-related activities which are more structural in nature, e.g. formal meetings, information sharing, documentation flows, and having joint meetings between the depending functions, which are all activities easier to quantify and control. Furthermore, collaboration is characterized as more mutual process more related to behavior as it represents the unstructured nature of interdepartmental relations, where the dependent functions carrying out work together with common goals, visions and where resources are shared, beyond cooperation and interaction. This is in line with Lawrence and Lorsch $(1986,1967)$ who thought of integration as a process consisting of a unified effort by various subsystems to accomplish company tasks and the demands of the competitive environment. Many studies have been carried out in the field of interdepartmental integration in NPD. However, most of them focus on either interaction (Gupta et al., 1985, 1986a; Song et al., 1998) or collaboration (Moenaert et al., 1994; Souder, 1988; Dougherty, 1992), but rarely the two combined, and specifically during the early phase.

In studying collaboration and interaction as different mechanisms for integration, Kahn argues for a deeper understanding of the differences which may enable different combinations during different phases of NPD, and in relation to the organizational context. While many argue for increased integration through more meetings across functions, Kahn found that interaction might decrease the performance of the project, as more meetings are not seen as productive when it comes to improving the relationship between the depending functions.

On the contrary, it can be argued that increased interactions in terms of joint meetings between marketing and R\&D may be necessary as an enabler of increased collaboration during the early phase between marketing and R\&D. Studies related to general NPD indicate that managers use interaction to establish familiarity and common views regarding what to focus on between the functions involved, from which collaboration will slowly emerge (Bernasco et al., 1999).

Insights into departmental integration which solve and reduce the level of negative conflicts during the early phase of NPD may contribute to an increased level of understanding of the nature of dependencies, as conflicts may express strong interdependencies. This may contribute to increasing knowledge concerning the difficulties of creating a thorough concept during the early phase of NPD.

\section{Methodology}

This case is based on a study of the conceptual work undertaken during the early phase of NPD at an ECM. The strongest and most problematic relations have been 
found to exist between R\&D and marketing, even though dependencies were also found as regards the functions of design, manufacturing, finance, and purchasing during the early phase of NPD. Continuously, we will focus on the interrelationships between marketing and $\mathrm{R} \& \mathrm{D}$ as the major difficulties have been experienced when combining these perspectives in order to create a common concept during the early phase. The case reports real-time change when dealing with conflicts and the integration of functional perspectives between marketing and R\&D.

This study is based on a qualitative methodology (Denzin, 2000; Silverman, 1993). While a quantitative method is primarily aimed at providing nomological knowledge enabling predictions, a qualitative methodology emphasizes a broader range of perspectives on complex interrelationships within a more limited number of empirical entities. Since this study is based on one single company, ECM, it is pertinent to speak of a case study approach (Eisenhardt, 1989; Yin, 2002). Case studies include a number of various applicable methodologies that complement one another. In this study, a combination of participant observations (Atkinson and Hammersley, 1994), interviews (Kvale, 1996), and the studying of formal documents has been used.

Participant observations are based on an ethnographic method whereby the researcher spends some time within the community being researched; a society, an organization, and a specific group of interests. The ethnographic method is used when the researcher wants to understand all the local idiosyncrasies and to pay attention to the subtle nuances of a specific culture or community. The participant observations included observations made at workshops, executive meetings, weekly and monthly meetings, and other formal or semi-formal administrative arrangements taking place at ECM during the autumn of 2003 and the spring of 2004, totalling 20 hours. During these meetings and workshops, detailed field-notes were made, including observations of actual activities as well as more personal reflections on the progress of the discussions and other relevant issues. These field-notes were transcribed, analysed, and filed. The ethnographic approach has been used in organizational studies at manufacturing companies (Dalton, 1959; Burawoy, 1979), service companies (Hochschild, 1983), and knowledge-intensive companies (Kunda, 1992).

The interview methodology, which is complementary to participant observation, is based on a hermeneutic approach whereby discussions with the interviewees are subject to interpretation. While the participant observation is useful in relationships and in certain interactions in an organization, the interview methodology is more focused on an understanding of the individual interviewee's ideas and perspectives on his or her day-to-day activities. There were 30 interviews with the relevant staff from the marketing, R\&D, Design, Finance, Project Management, and Manufacturing departments of ECM. The managers were both male and female, representing different areas and nationalities. During the interviews, a semi-structured interview manual was used, albeit together with the opportunity to discuss interesting emerging issues outside the scope of this manual. The interviews lasted for about 1.5 hours on average. All interviews were transcribed and analysed by the researcher and then discussed with fellow researchers.

The documents included are the formal documentation of marketing and R\&D involved during the process of the early phase, including descriptions, processes, and minutes from meetings. These documents have primarily been used to attain an understanding of the nature of conflicts and integration.

\section{Managing the balance of perspectives}


EJIM

9,1

The researcher employed here is currently working in, and has extensive experience of, the automotive industry. This close connection with the case being studied offers the advantage of having a deep understanding of the underlying mechanisms and issues, as well as insight into and access to the organization. Despite the apparent advantages of the insight that this setup provides, a great deal of effort has gone into clarifying and resolving any biases in perception, pre-understandings, and interpretations of the empirical material. This has been achieved by constantly challenging the interpretations of the respondent accounts and by inviting fellow researchers solely belonging to academia to assist in the interpretations. In doing so, a balance is created that will safeguard critical reflection. Here, one could talk about an insider/outsider research team (Bartunek and Louis, 1996). The downsides associated with "going native" (Alvesson, 1999), or the potential biases, are easily offset by the additional insight that researchers enjoy in comparison with fully academy-departmental researchers. Basically, two strategies for safeguarding reliability, i.e. respondent validation and inter-rating (Van de Ven and Poole, 1990), have been applied. Validation of the analysis has been carried out by means of reviews and discussions with respondents and managers, and in the community of researchers, in order to achieve consistent interpretations.

\section{The case of ECM}

$E C M$

ECM being studied here is a relatively small but profitable carmaker in the premium segment. A major corporation owns the company within the automotive industry, with a multiple brand portfolio. During recent years, the product portfolio of ECM has grown and its future growth plans imply a further increase in its product portfolio and, subsequently, even more products needing to be developed. The maturity of the industry intensifies the need to prioritize, from the cost perspective, while still developing competitive and unique products that have a clear position in the marketplace. Combined with shorter product development times, a shared platforms strategy, and shared technological development in several areas, increased product development leads to increased levels of complexity during NPD, causing a sense of urgency as regards resolving conflicts and increasing the level of integration between marketing and R\&D during the early phase of NPD. This case illustrates the emergent increased focus and change vis-à-vis how marketing and R\&D work together to define a more thorough concept.

\section{Problem background}

In the meetings held between marketing and $R \& D$ during the early phase prior to the development project starting, there are already too many detailed issues to discuss and merge. The different functions have done their homework and have already prepared documents describing the product from their specific points of view. R\&D often has a document describing the product content on the system level, together with the estimated cost. The documents that marketing has developed concern the product attributes in relation to the desired positioning of the vehicle, based on customer target groups and the competition, as well as a description of the vehicle on a more detailed level with specifications of the engine types, power train, platform, body types, etc. When exchanging information and 
ideas during the early phase, this is mostly done by sharing documents between the departments and through some informal meetings.

\section{Conflicting ways of working between marketing and $R \& D$}

At this point in time, there has not been very much cooperation and the receivers of the documents often react in relation to their view within their function, expressed thus by one manager in R\&D:

The initial product description we get from Marketing needs to be translated before being submitted to the engineers; this is because their description is too general and not sufficiently defined. This causes the R\&D people to see the description as a "wish list" rather than the description of a product to be developed. We thus need to make it more specific, while keeping it on a general level from the R\&D perspective (Manager 3, R\&D).

At this point in time, R\&D are facing the need for detailed planning, also seeing it as their responsibility to make the vehicle more concrete and translate the description into a specification that is possible to develop within the financial and technical framework they have identified. It is noted that the R\&D staff take on that work themselves and do not get back to marketing for clarification or to work it out together. A manager further illustrates this thus:

One issue concerning conflicts is that we work differently. Marketing use relative definitions regarding an attribute definition, while R\&D use a technical specific solution to describe the attribute. Over time, this causes a problem as at one stage, the departments can agree on the different definitions, while at a later stage, Marketing has a different interpretation that is based on changes in the marketplace, etc. An example of this is that Marketing might state that the vehicle needs to be "leading in performance", without saying what that is. Thus, we need to define it into functions and systems, as we need to have it on a detailed solution level in order to calculate the development cost. This causes a lot of problems (Manager 8, R\&D).

This has also been expressed by others and can partly be interpreted in terms of marketing and R\&D carrying out conceptual work very differently and partly in terms of when marketing is going through the more conceptual phase, R\&D is already oriented towards problem-solving. This causes conflicts. Furthermore, at this point, preconditions seem to have been set which are not being discussed between the functions, expressed thus by one manager;

In our meetings, we rarely discuss the vision of the product and what we want the product to stand for in relation to possibilities and restrictions, from our different perspectives. I see this as a shortcoming as we later on end up with conflicting views about what the product represents during the development phase, and with a product content that is too costly but at the same time not unique or differentiated enough. The conflicts we go through early on are often related to solutions and specifications, so we start here and not with the vision (Manager 4, Marketing).

The departments already seem to be locked into solutions and there are many conflicting issues. Something that is not brought up is the vision of the product, what it represents, and the further attributes that make up the car. Instead, a lot of detailed work has been carried out within each function without having had a common and more general discussion about what to develop or a common goal. Furthermore, regarding the cooperation and relations between marketing and R\&D during the initial meetings, a marketing manager expressed the differences and complexities thus;

\section{Managing the balance of perspectives}




\section{EJIM 9,1}

In the discussions that we have when we meet, with our various developed documents, we are too focused on our own issues and complexities and fail to make others understand. I think it is a problem that we do not listen or understand enough of each other's problems (Manager 12, Marketing).

Historically, it has been taken for granted to some extent that the differences in points of view regarding what the vehicle should be, and its content, will be solved as development proceeds. Not much effort has gone into looking into the differences of the various functions during the early phase. Often, these issues have grown into major problems during the development phase, becoming costly when solved later on. This is because the cost of change increases the further a project advances.

In the past, the various new car projects have carried out part of their concept development within the project. Too often, the concept changes completely because the holistic view does not make sense with regard to positioning, product cost, estimated volumes, etc. One reason for this is probably that the concept has not been thoroughly developed and when the project enters a certain phase, it then becomes a problem. A case in point is project A1 where we had a strong industrial and cost focus which led to a good level of detail early on, but we had no common understanding of what the vehicle was to represent and so the content was not competitive or differentiated enough and the design was poor. This was discovered at a late stage and we had to stop the project (Manager 14, R\&D).

The risk, however, of continuing with this process is that the definitions of the products will be the ones the project believes in, and not the ones decided upon in the strategic plan. Consequently, there will be a high risk of developing competing products - more of the same - not products that are differentiated enough. Based on observations, the different functional works and documents are rarely compared in order to identify gaps or conflicting issues. This indicates that there is a lack of intensive collaboration and more interaction between marketing and R\&D. Not dealing with these gaps may be one reason why development projects need to re-work some of their conceptual input later on during the development phase, as too many contradictions are built in.

\section{The emerging change when managing the early phase - beyond conflicts}

From observations and interviews, the challenge of expanding the product portfolio, while at the same time facing cost reduction targets in R\&D, has led to an increased focus on how to improve work on concept definition during the early phase.

We have known that we did not have a thorough concept early on as we in Marketing and R\&D have not always agreed, but we have felt that it has been good enough as there was no total failure of any car project with regard to market acceptance. The kind of failure we have experienced has mostly concerned cost and detailed content. We have not put in the effort to come to full understanding during the conceptual phase as we have allowed the concept to evolve during the development phase, which then drives cost and may not always create strong and distinct products. In those areas, we now have to improve and agree on a thorough concept during the early phase (Manager 3, R\&D).

The difference in requirements that was causing conflicts between marketing and R\&D seems to have come to the surface. Until recently, each function has had a decision board consisting of executive managers from different functions. One unclear issue has been the scope of each decision board. 
There have been too many forums for issues in early phase that 4-5 persons in the company need to come around. Even though we have had attendees from "the other side" in both structures, this has been more as observers and conflicting issues have not been brought up, as the focus has not allowed that. The complexity probably creates this. Changing this into a common meeting structure jointly chaired by the Heads of Marketing and R\&D, we hope to obtain a better understanding of what the common issues are and at which point in time to work on those (Manager 23, R\&D).

A similar statement was also made by another manager, but this time from marketing;

Looking at the agendas of the different meetings that have previously taken place, these seem to be very similar but to come from different angles, yet with the same headings (Manager 1, Marketing).

The different boards for strategic decisions concerning the early phase of NPD brought up issues of a cross-functional nature. Thus, the members of these boards are representatives of the different functions. But this did not seem to be enough to solve the conflicting issues as the perspectives on the decisions often reflected one of the perspectives since the preparations were not made by means of collaboration. The balance of perspectives in the meetings was not good enough.

With the experienced problems on the meeting structures and the changes of the common documentation based on the simulation tool R\&D initiated, the need to solve conflicting views and for more collaborative work was brought up. Instead of the different functional meetings with representatives from other functions, a common meeting structure where R\&D and marketing have co-chairmanship of the meetings has been set up with the purpose of having a more transparent process, and to be seen as a step towards further collaboration between the departments.

The responsible executive managers chair this meeting structure together. The agendas imply that a lot of work needs to be done in terms of preparations, and also by means of collaboration, as the various perspectives are on the agenda. The different groups of meetings in the structure are also co-chaired by representatives of Marketing and R\&D, and these are jointly responsible for presenting the holistic picture of the respective issues (Manager 4, Marketing).

The integrative management process is made up of a top-management decision meeting that is co-chaired, with a supporting structure of preparatory forums dealing with concept, technology, systems and strategy which compose the agenda of the top-management meeting. Each of the underlying forums is also co-chaired by marketing and R\&D and implies mutual responsibility.

When developing this new meeting structure, one manager expressed his view of the changes thus;

As the executive managers from R\&D and Marketing have come to the understanding here that close collaboration is the only way forward, they are also sending out signals to others that this is what is required of all of us. We need to create a more constructive way of solving all the complex issues while at the same time retaining the holistic view, even if we may not always agree (Manager 8, R\&D).

The power struggles between the functional units of marketing and R\&D seem to have been perceived as non productive and transformed into a more fruitful collaboration on a high level between the executive managers. There seems to be an understanding

\section{Managing the balance of perspectives}




\section{EJIM 9,1}

\section{4}

among the managers in marketing and $R \& D$ as regards the need to have a more constructive relationship between the functions of the early phase of NPD and that the identified way towards achieving that is via increased integration. Throughout the case, increased collaboration is often mentioned as a need to create more thorough concepts.

\section{Discussion}

This case study of ECM illustrates the difficulties of creating a thorough common concept during the early phase of NPD, but now a sense of urgency has emerged with regard to improving the concept creation and management of the early phase of NPD. Very early on in the discussions regarding a new product held between marketing and R\&D, detailed issues are brought up. It seems to have been problematic that marketing and R\&D have made assumptions based on their own perspectives rather than first having a joint discussion concerning the vision of the product in order to secure a common understanding of the needs, priorities, opportunities, and restrictions to be considered during development of the concept. Taken to this level, work can be very problematic as the different functions have separately developed their own ideas about the concept within the framework of each discipline, thus lacking a holistic view and a common goal. When representatives from the different functions meet trying to merge the different conceptual views, a debate arises. The differences in the views, standpoints, and reasoning of the functions involved, based on the differences in the focus, definitions, and complexities of each discipline, then cause conflicting views. Even though collaboration exists between the depending functions, through formal and informal meetings and contacts, conflicts tend to arise which are not easily solved.

Clarifying the concept during the early phase in order to guide further development has been identified as one of the greatest opportunities for improving the overall NPD process and market success of a new product. The creation of a thorough concept has, however, been shown to be difficult, and something that many companies fail to do (Murphy and Kumar, 1997; Khurana and Rosenthal, 1997). Nevertheless, less detailed accounts are available from the literature as regards why it is difficult to create a thorough concept during the early phase, as well as what the barriers and underlying causes are and how to overcome these barriers. From this case study of ECM, the increased focus on the early phase seems to be grounded in the understanding that the many conflicts and misunderstandings have become a barrier to the development of more thorough concepts via collaboration between marketing and R\&D. To move away from the many negative conflicts and enable far-reaching integration, the case indicates the necessity to develop understanding of the nature of the strong interdependencies, and where those lie, in order to create a more productive view of the merging of perspectives when creating a new product. When developing the new integrative meeting structure, set up via collaboration between marketing and R\&D, the similarities of the previous different decision boards' agendas and focus illustrate the inbuilt dependencies and the different perspectives of the issues. It is necessary to bring these different perspectives into the same discussion, and not have them in different forums, in order to make the dependencies more explicit and bring understanding to complexities and the nature of dependencies. These findings contribute to theory regarding why concept creation is difficult to accomplish during the early phase of NPD. They further contribute to understanding of how to 
create far-reaching integration based on collaboration and interaction between marketing and R\&D.

Even if the emerging changes illustrated in the case are related to increased levels of interaction and cooperation between the functions, which according to Kahn (1996) may not improve the performance of the project, the underlying understanding connected with this seems to be the need for more collaboration between the units of marketing and R\&D enabled by a deeper understanding of the different perspectives and interdependencies. We argue that the required understanding needs to concern the different perspectives, problems, and priorities, but may also be more important concerning the dependencies, and that dependencies entail the necessity of collaboration when creating something new. Increased integration is further argued to remove negative attitudes and behaviors resulting from specialization and to further build trust and conflict-resolution mechanisms (Hauptman and Hirji, 1999). One could argue here, based on Kahn's analysis, that collaboration is better at increasing integration as it is based on deep insight into the interdependencies, while interaction lacks such insight. Nevertheless, interaction designed for collaboration may enable insight into the interdependencies. When designing the new meeting structure at $\mathrm{ECM}$, the focus has been on increased collaboration and the structure has been managed jointly by R\&D and marketing, with joint chairmanship being held by the executives of marketing and R\&D. Furthermore, the structure is based on collaboration during the preparations and can be seen as an initial step towards enabling increased collaboration. Such a managerial process may further develop an understanding of the areas where increased collaboration is needed, as well as those where the interaction is sufficient. Just because a high degree of integration is prescribed to the early phase, this has to be balanced against the need for specialization. Functional specialization is important as the expertise available in the different functions is essential when making the conceptual definitions during complex product development (Leonard-Barton et al., 1994). Studies have further shown that integration as such does not necessarily lead to increased performance (Gomes et al., 2003). Thus, it is again essential to understand where the interdependencies are at their strongest and which areas are crucial when creating a common concept and considering which level of integration is needed. In certain areas, formal meetings and reports may be enough, while in respect of other issues, intensive collaboration may be crucial (Gomes et al., 2003; Kahn, 1996).

The notion of NPD as a multidisciplinary process where market and technology knowledge is developed and synthesized into a product implies reciprocal task interdependency between the different disciplines and thus requires a high level of integration between the perspectives (Brown and Eisenhardt, 1995; Griffin and Hauser, 1996; Griffin, 1997). Even though NPD is a multidisciplinary process, research has shown that the strengths of the interdependencies vary over the development cycle and that the strongest interdependency during the early phase is found to be between marketing and $\mathrm{R} \& \mathrm{D}$, which is why far-reaching integration is argued to be necessary between marketing and $R \& D$ when creating the concept during the early phase (Gomes et al., 2003; Griffin, 1997). Interdependencies per se have further been identified as the fundamental cause of inter-group conflicts (Brett and Rognes, 1986; Ruekert and Walker, 1987; Walton and Dutton, 1969), which can to some extent be seen as natural since knowledge development occurs around divergences and when bringing in different views (Galbraith, 1982). Nevertheless, conflicts may become a strong barrier
Managing the balance of perspectives 
EJIM

9,1

56 to integration (Crawford, 1977) as they tend to allow divergent ideas to emerge as regards what constitutes the concept (Griffin, 1997; Hayes et al., 1988).

In the new meeting structure, the scope has been broadened to also include platform and architecture development and the technology strategy. This may shed light on dependencies which have not been dealt with previously and which may have a strong impact on concept development, contributing to misunderstandings and conflicts. The background to many disagreements may be caused by other dependencies than the ones between those functions; dependencies outside the scope of the cooperation. This implies a need to widen the scope to include more than the specific products and such issues as product architecture, platform development, technology strategy, and portfolio strategy in more intensive collaboration than is the case today. The initial steps taken in collaborating need to pave the way for wider collaboration, not only with regard to the dependencies known today but maybe also with regard to creating new dependencies based on the jointly developed perspective of the early phase. It is thus suggested that a contingency approach be applied when looking into the management of the early phase of NPD, as the emerging focus on the early phase would in this case seem to be related to changes in other circumstances, e.g. an increased cost focus, the sharing of solution development, and platforms between brands, making the early phase more important for ECM. Continuous reflection on the integration gap (Gupta et al., 1986a) is further suggested here; looking into where integration is needed compared to where far-reaching integration has been achieved.

\section{Conclusions and managerial implications}

In this case study of ECM, which has been successful over a long period of time in developing new products with a high level of profitability, the early phase may have been fairly well executed. When continuing this trend in an environment characterized by increased complexities in NPD and with an increased proportion of development between brands, the importance of managing the early phase increases. When creating the vision of the product, the critical properties and characteristics need to be identified, something which will further be explored in order to define the product specification at the level the concept requires. Strategic choices regarding properties need to be made in relation to the positioning of the product and the technological potential. Making these strategic choices at an early stage becomes more important as the level of complexity increases, with joint development between the brands and suppliers of the industry.

As integration between marketing and $R \& D$ continues and new knowledge is developed via collaboration, new capabilities and possibilities may emerge, when viewed from a different perspective than previously, which might create new, innovative, and competitive products (Kim and Wilemon, 2002b). Suggestions made here based on the case of ECM are; a further-developed organizational structure supporting integration by giving R\&D and marketing joint responsibility for new product strategy development, establishing liasoning positions for implementing and developing processes, and continuing to hold regular joint $\mathrm{R} \& \mathrm{D} /$ marketing meetings with senior management. Findings from other cases further support the current findings regarding these matters (Kahn, 1996; Gupta and Wilemon, 1991). This will further enable understanding of each other's functional perspectives, in terms of complexities, relations, priorities and problems, which is a pre-requisite for further 
collaboration and integration as well as having a common objective and vision. The role of top management is to provide support using visions, secure a balance of power between R\&D and marketing, make certain decisions joint ones, and become involved in early discussions wherein the visions are elaborated on.

The results of this single case provide valuable insight into managing the early phase of the NPD process. Nevertheless, further research and longitudinal studies are recommended in order to move towards a more comprehensive understanding of the early phase.

\section{References}

Alvesson, M. (1999), Methodology for Close Up Studies - Struggling with Closeness and Closure, School of Economics and Management, University of Lund, Lund.

Atkinson, P. and Hammersley, M. (1994), "Ethnography and participant observation", in Denzin, N.K. and Lincoln, Y.S. (Eds), Handbook of Qualitative Research, Sage, Thousand Oaks, CA, pp. 248-61.

Bartunek, J.M. and Louis, M.R. (1996), Insider/Outsider Team Research, Qualitative Research Methods, Sage, Thousand Oaks, CA.

Bernasco, W., Weerd-Nederhoof, P.C., Tillema, H. and Boer, H. (1999), "Balanced matrix structure and new product development process at Texas instruments materials and controls division", R\&D Management, Vol. 29 No. 2, pp. 121-31.

Bourgeois, L.J. (1980), "Performance and consensus", Strategic Management Iournal, Vol. 1 No. 3, pp. $227-48$.

Bowen, H.K., Clark, K.B., Holloway, C.A. and Wheelwright, S.C. (1994), "Development projects: the engine of renewal", Harvard Business Review, Vol. 72 No. 5, pp. 110-20.

Branstad, P., Williams, T. and Rodewig, T. (1999), "Challenges facing the global automotive industry", Insights: Consumer and Engineered Products, Vol. 1 No. 1, pp. 1-8.

Breitsprecher, C., Toulemonde, G. and Lache, R. (2004), Global Automotive Industry. The Drivers: How to Navigate the Auto Industry, Deutsche Bank, Frankfurt am Main.

Brett, J.M. and Rognes, J.K. (1986), "Intergroup relations in organizations", in Goodman, P. (Ed.), Designing Effective Work Groups, Jossey-Bass, San Francisco, CA.

Brown, S.L. and Eisenhardt, K.M. (1995), "Product development: past research. Present findings and future directions", Academv of Management Review, Vol. 20 No. 2, pp. 343-78.

Burawoy, M. (1979), Manufacturing Consent: Changes in the Labour Process under Monopoly Capitalism, University of Chicago Press, Chicago, IL.

Clark, K., Chew, B.W. and Fujimoto, T. (1987), "Product development in the world auto industry", Brookings Paber on Economic Activitu, No. 3, pp. 729-82.

Crawford, C.M. (1977), "Product development: today's most common mistakes", University of Michigan Business Review, Vol. 29 No. 1, pp. 1-7.

Dalton, M. (1959), Men Who Manage: Fusion of Feeling and Theory in Administration, Wiley, New York, NY.

Denzin, N.K. (2000), "The practices and politics of interpretation", in Denzin, N.K. and Lincoln, Y.S. (Eds), Handbook of Qualitative Research, Sage, Thousand Oaks, CA, pp. 897-922.

Dougherty, D. (1992), "A practice-centered model of organizational renewal through product innovation”, Strategic Management Journal, Vol. 13 No. 1, pp. 77-92.

Eisenhardt, K.M. (1989), "Building theories from case study research”, Academv of Management Review, Vol. 14 No. 4, pp. 532-50.

\section{Managing the balance of perspectives}




\section{EJIM 9,1}

Galbraith, J.R. (1982), “Designing the innovating organization”, Organizational Dvnamics, Vol. 10 No. 3, pp. 3-24.

Gomes, J.F.S., Weerd-Nederhof, P.C., Pearson, A.W. and Cunha, M.P. (2003), "Is more always better? An exploration of the differential effects of functional integration on performance in new product development”, Technovation, Vol. 23 No. 3, pp. 185-91.

Griffin, A. (1997), "The effect of project and process characteristics on product development cycle time”, Journal of Marketing Research, Vol. 34 No. 1, pp. 24-34.

Griffin, A. and Hauser, J.R. (1992), "Patterns of communication among marketing, engineering and manufacturing - a comparison between two new product teams", Management Science, Vol. 38 No. 3, pp. 360-73.

Griffin, A. and Hauser, J.R. (1996), "Integrating R\&D and marketing: a review and analysis of the literature”, Lournal of Product Innovation Management, Vol. 13 No. 3, pp. 191-215.

Gupta, A.K. and Wilemon, D. (1991), "Improving R\&D/marketing relations in technology-based companies: marketing's perspective”, Lournal of Marketing Management, Vol. 7 No. 1, pp. 25-45.

Gupta, A.K., Raj, S.P. and Wilemon, D. (1985), "The R\&D - marketing interface in high-technology firms", Journal of Product Innovation Management, Vol. 2 No. 1, pp. 12-24.

Gupta, A.K., Raj, S.P. and Wilemon, D. (1986a), “A model for studying R\&D - marketing interface in the product innovation process", Lournal of Marketing, Vol. 50 No. 1, pp. 7-17.

Gupta, A.K., Raj, S.P. and Wilemon, D. (1986b), "R\&D and marketing managers in high-tech companies: are they different?", IEEE Transactions on Engineering Management, Vol. 33 No. 1, pp. 25-32.

Hauptman, O. and Hirji, K.K. (1999), "Managing integration and coordination in cross-functional teams: an international study of concurrent engineering product development", $R \& D$ Management, Vol. 29 No. 2, pp. 179-91.

Hayes, R., Wheelwright, S. and Clark, K. (1988), Dynamic Manufacturing, Free Press, New York, NY.

Hochschild, A.R. (1983), The Managed Heart, University of California Press, Berkeley CA.

Kahn, K.B. (1996), "Interdepartmental integration: a definition with implications for product development performance", Iournal of Product Innovation Management, Vol. 13 No. 2, pp. 137-51.

Khurana, A. and Rosenthal, S. (1997), "Integrating the fuzzy front-end of new product development”, Sloan Management Review, Vol. 38 No. 2, pp. 103-20.

Khurana, A. and Rosenthal, S. (1998), "Towards holistic 'Front Ends' in new product development", Lournal of Product Innovation Management, Vol. 15 No. 1, pp. 57-74.

Kim, J. and Wilemon, D. (2002a), "Focusing the fuzzy front-end in new product development", R\&D Management, Vol. 32 No. 4, pp. 269-79.

Kim, J. and Wilemon, D. (2002b), "Strategic issues in managing innovation's fuzzy front-end", European Iournal of Innovation Management, Vol. 5 No. 1, pp. 27-39.

Koen, P., Ajamian, G., Burkart, R., Clamen, A., Davidson, J., D’Amore, R., Elkins, C., Herald, K., Incorvia, M., Johnson, A., Karol, R., Seibert, R., Slavejkov, A. and Wagner, K. (2001), "Providing clarity and a common language to the fuzzy front end", $\underline{\text { Research Technology }}$ Management, Vol. 44 No. 2, pp. 46-55.

Krishnan, V. and Ulrich, K.T. (2001), "Product development decisions: a review of the literature", Management Science, Vol. 47 No. 1, pp. 1-21.

Kunda, G. (1992), Engineering Culture, Temple University Press, Philadelphia, PA. 
Kvale, S. (1996), InterViewing, Sage, London.

Lawrence, P.R. and Lorsch, J.W. (1967), "Differentiation and integration in complex organizations", Administrative Science Quarterlv, Vol. 12 No. 1, pp. 1-47.

Lawrence, P.R. and Lorsch, J.W. (1986), Organization and Environment: Managing Differentiation and Integration, Harvard Business School Press, Boston, MA.

Leonard, D. and Straus, S. (1997), "Putting your company's whole brain to work", Harvard Business Review, Vol. 75 No. 4, pp. 111-21.

Managing the balance of perspectives

Leonard-Barton, D., Bowen, H.K., Clark, K.B., Holloway, C.A. and Wheelwright, S.C. (1994), "How to integrate work and deepen expertise", Harvard Business Review, Vol. 72 No. 5, pp. 121-30.

Moenaert, R.K. and Souder, W.E. (1990), "An information transfer model for integrating marketing and R\&D personnel in NPD projects", Iournal of Product Innovation Management, Vol. 7 No. 2, pp. 91-107.

Moenaert, R.K., Souder, W.E., De Meyer, A. and Deschoolmeester, D. (1994), "R\&D - marketing integration mechanisms, communication flows and innovation success", Lournal of Product Innovation Management, Vol. 11 No. 1, pp. 31-46.

Moenaert, R.K., De Meyer, A., Souder, W.E. and Deschoolmeester, D. (1995), "R\&D/marketing communication during the fuzzy front-end", IEEE Transactions on Engineering Management, Vol. 42 No. 3, pp. 243-58.

Montoya-Weiss, M.M. and O’Driscoll, T.M. (2000), "From experience: applying performance support technology in the fuzzy front end", Journal of Product Innovation Management, Vol. 17 No. 2, pp. 143-61.

Murphy, S. and Kumar, V. (1997), "The front-end of new product development: a Canadian survey", R\&D Management, Vol. 27, pp. 5-15.

Olson, E.M., Walker, O.C., Ruekert, R.W. and Bonner, J.M. (2001), "Patterns of cooperation during new product development among marketing, operations and R\&D: implications for project performance", Iournal of Product Innovation Management, Vol. 18 No. 4, pp. 258-72.

Rein, G.L. (2004), "From experience: creating synergy between marketing and research and development", Iournal of Product Innovation Management, Vol. 21 No. 1, pp. 33-44.

Ruekert, R.W. and Walker, O.C. (1987), "Marketing's integration with other functional units: a conceptual framework and empirical evidence", Iournal of Marketing, Vol. 51 No. 1, pp. 1-19.

Shaw, V., Shaw, C.T. and Enke, M. (2003), "Conflict between engineers and marketers: the experience of German engineers", Industrial Marketing Management, Vol. 32 No. 6, pp. 489-99.

Silverman, D. (1993), Interpreting Qualitative Data, Sage, Thousand Oaks, CA.

Song, X.M. and Parry, M.E. (1997a), "A cross-national comparative study of new product development process: Japan and the United States", Journal of Product Innovation Management, Vol. 61 No. 2, pp. 1-18.

Song, X.M. and Parry, M.E. (1997b), "The determinants of Japanese new product success", Lournal of Marketing Research, Vol. 34 No. 1, pp. 64-76.

Song, X.M., Thieme, R.J. and Xie, J. (1998), "The impact of cross-functional joint involvement across product development stages: an exploratory study", Lournal of Product Innovation Management, Vol. 15 No. 4, pp. 289-303.

Souder, W.E. (1977), "Effectiveness of nominal and interacting group decision processes for integrating R\&D and marketing", Management Science, Vol. 23 No. 6, pp. 595-606. 
EJIM

9,1

60

Souder, W.E. (1988), "Managing relations between R\&D and marketing in new product development projects", Iournal of Product Innovation Management, Vol. 5 No. 1, pp. 6-19.

Souder, W.E., Sherman, J.D. and Davies-Cooper, R. (1998), "Environmental uncertainty, organizational integration, and new product development effectiveness: a test of contingency theory”, Journal of Product Innovation Management, Vol. 15 No. 6, pp. 520-34.

Thomke, S. and Fujimoto, T. (2000), "The effect of 'front-loading' problem solving on product development performance", Lournal of Product Innovation Management, Vol. 17 No. 2, pp. $128-42$.

Walton, R.E. and Dutton, J.M. (1969), "The management of interdepartmental conflict: a model and review", Administrative Science Quarterly, Vol. 14 No. 1, pp. 73-84.

Van de Ven, A.H. and Poole, M.S. (1990), "Methods for studying innovation development in the Minnesota innovation research program”, Organization Science, Vol. 1 No. 3, pp. 313-35.

Verganti, R. (1999), "Planned flexibility: linking anticipation and reaction in product development projects", Iournal of Product Innovation Management, Vol. 16 No. 4, pp. 363-76.

West, P. (2000), Organizational Learning in the Automotive Sector, Routledge, London.

Wheelwright, S.C. and Clark, K.B. (1992), Revolutionizing New Product Development, Free Press, New York, NY.

Yin, R.K. (2002), Case Study Research, Design and Methods, Sage, Thousand Oaks, CA.

\section{Corresponding author}

Kamilla Kohn can be contacted at kamilla@fenix.chalmers.se

To purchase reprints of this article please e-mail: reprints@emeraldinsight.com Or visit our web site for further details: www.emeraldinsight.com/reprints 


\section{This article has been cited by:}

1. Amy-Jane Troy, Joe Bogue. 2015. Simulation modelling. British Food Journal 117:2, 943-962. [Abstract] [Full Text] [PDF]

2. Vinayak Kalluri, Rambabu Kodali. 2014. Analysis of new product development research: 1998-2009. Benchmarking: An International Journal 21:4, 527-618. [Abstract] [Full Text] [PDF]

3. Hyunjung Lee, Stephen K. MarkhamWe-ness, Knowledge Sharing, and Performance in New Product Development Teams 181-194. [CrossRef]

4. Cik Rohaida Binti Saarani, Norhani Bakri. 2012. Examining The Technical and Non Technical Member's Participation in Cross-Functional Teams: A Case Study. Procedia - Social and Bebavioral Sciences 40, 187-196. [CrossRef]

5. Marion A. Weissenberger-Eibl, Benjamin Teufel. 2011. Organizational politics in new product development project selection. European Journal of Innovation Management 14:1, 51-73. [Abstract] [Full Text] [PDF]

6. Eric Brun, Alf Steinar Saetre, Martin Gjelsvik. 2009. Classification of ambiguity in new product development projects. European Journal of Innovation Management 12:1, 62-85. [Abstract] [Full Text] [PDF]

7. Thomas Magnusson, Glenn Johansson. 2008. Managing internal technology transfer in complex product development. European Journal of Innovation Management 11:3, 349-365. [Abstract] [Full Text] [PDF]

8. Stefanie Bröring, Philipp Herzog. 2008. Organising new business development: open innovation at Degussa. European Journal of Innovation Management 11:3, 330-348. [Abstract] [Full Text] [PDF] 